\title{
Physical-Mathematical Foundations of the Penman Equation from the Perspective of the First Law of Thermodynamics and Energy Balance Theory
}

\author{
Martín Mundo-Molina ${ }^{1}$, Enrique De Coss-Gomez ${ }^{2}$ \\ ${ }^{1}$ Investigation Centre Faculty of Engineer Autonomous, University of Chiapas, Tuxtla Gutierrez, Mexico \\ ${ }^{2}$ Investigation Centre CIDESTA, Tuxtla Gutierrez, Mexico \\ Email: ic_ingenieros@yahoo.com.mx,cidestachi@yahoo.com.mx
}

How to cite this paper: Mundo-Molina, M. and De Coss-Gomez, E. (2017) Physical-Mathematical Foundations of the Penman Equation from the Perspective of the First Law of Thermodynamics and Energy Balance Theory. Journal of Water Resource and Protection, 9, 1377-1390.

https://doi.org/10.4236/jwarp.2017.912088

Received: October 1, 2017

Accepted: November 18, 2017

Published: November 21, 2017

Copyright $\odot 2017$ by authors and Scientific Research Publishing Inc. This work is licensed under the Creative Commons Attribution International License (CC BY 4.0).

http://creativecommons.org/licenses/by/4.0/

\begin{abstract}
The evapotranspiration is indispensable for the planning and management of water resources in watersheds and for the design of important engineering projects. The accuracy of its estimation depends, among other things, on the proper determination of the date and frequency of irrigation. One of the most accurate equations for estimating the reference crop evapotranspiration (ETo) is the Penman-Monteith equation, which was derived from the Penman equation published in 1948, which in turn is based on the energy balance equation. In this paper we present the theoretical foundations of Penman's equation from the perspective of the first law of thermodynamics and the theory of energy balance as a contribution for the students and engineers who use Penman's or Penman-Monteith equations in a utilitarian way within the historical and theoretical framework of the origin of this equation.
\end{abstract}

\section{Keywords}

Evapotranspiration, Penman, Penman-Monteith, Irrigation Requirement

\section{Introduction}

The evapotranspiration (ET) understood as the sum of soil evaporation and plant transpiration plays an important role in regional water planning and management. Hydrological models that include water management and crop growth require an accurate estimation of ET [1] [2] [3] [4] [5]. The accuracy of this estimate is especially important in order to plan the equitable distribution of 
water [6], for example for agricultural use, water supply projects to populations and for industrial or recreational use. Hydraulic projects also require a precise estimation of evapotranspiration for the planning, design and successful operation of projects [7]. In irrigation systems, forecasting of the reference crop evapotranspiration (ETo) is required to estimate water demand of crops in order to plan the volume of water that must be stored in the systems' dams. Therefore, the ETo is intimately linked to irrigation scheduling and management, with a correct estimation depending on the crops water supply [8] [9] [10]. The precise estimation of ETo is important in the programming, planning and management of irrigation systems and for other studies related to water [11]. Due to its relevance for its utilitarian nature, many methods have been published to estimate evapotranspiration. Empirical equations, methods, concepts and the theoretical elements of evapotranspiration have been developed for more than 130 years. The historical development of this subject is summarized below, without pretending to cover all of its aspects, rather only those that in the opinion of the author are the most relevant, highlighting specifically the contributions of the Penman and Penman-Monteith equations.

\section{Background}

In 1887 in the United States of America, experimental stations were begun to be established in the area of agriculture to determine the water needs of crops. One of the first "formal" studies that were reported was conducted at the University of Colorado campus in Fort Collins [12]. Thus, compared to other branches of science, scientific research on evapotranspiration is recent. It is estimated that the first studies on consumptive use began in 1900, although it was not yet applied to the water consumption of crops [13]. In those years, there was already talk of consumptive water use, a term that was possibly coined in the USA where the first studies and field tests began to determine seasonal consumptive use [14] [15] [16] [17] [18]. In 1913, Brigs and Shantz studied the water needs of 55 different crop varieties based on meteorological studies in Colorado, USA [19]. It wasn't until the 1920's when the concept of energy balance in the study of evapotranspiration in crops was first used [20]. After the 1920s, efforts were made to better define consumptive use for irrigation purposes, one of which was proposed by the American Society of Civil Engineering (ASCE) Water Committee. This committee defined consumptive use as "...the amount of water absorbed and transpired directly by a crop for it development, plus water evaporated from the soil."

It was until 1924 that Hedke developed one of the first methods to estimate ET based on air temperature in order to estimate the consumptive use of crops in the Rio Grande Valley [21]. In addition, in a report published by the State of California in 1930, consumptive use was defined as: “...the sum of the water used in the transpiration of the plant in its vegetative growth, plus water evaporated from the surface of the soil" [22]. In the 1930's and early 1940's, several re- 
searchers and organizations, among the most important being The Committee on Absorption and Transpiration of the Hydrology section of the American Geophysical Union, The Special Committee on Irrigation Hydraulics of the American Society of Civil Engineers, and The National Resources Committee, realized efforts to not only standardize the concept but to define it according to the physics of the phenomenon [12]. In the 1940's, the concept of evapotranspiration was understood as the sum of water evaporated from the soil plus that which the plant transpires through its stomata.

For irrigation purposes the term has had several definitions, for example: potential evapotranspiration, which was proposed in the late forties by Penman and Thornthwhite. According to Penman, potential evapotranspiration is the maximum rate of evaporation of water in the soil plus the transpiration of a green crop, without limitations in the irrigation water supply, on a surface that is completely shaded by the crop [12]. In 1942 there were authors who denominated the consumptive use of total evaporation as “...the sum of the water losses of a given area, constituted by the transpiration of vegetation, plus the evaporation of water surfaces, plus the evaporation of soil water". It is worth noting that this definition was applied to watersheds [12]. The concept of consumptive use applied to watersheds was denominated several ways, among others: evaporation, evapotranspiration, total losses and losses of water.

In this context, in 1948 Thornthwaite developed an empirical formula for calculating the evapotranspiration potential (ETp) that related to the experimental results of ETp with data of average monthly temperatures [23]. In the same year, Penman combined the energy balance equation and the aerodynamic equation (known as the combined equation) for energy balance studies. The Penman equation 1948 was established as the first mathematical expression with physical basis for calculating potential evapotranspiration, and for this reason, in addition to its precision and for serving as the foundation of the Penman-Monteith equation, it is one of the most widely used methods in the world [24]. This set of studies in the 1940's allowed a leap in scale, not only in the knowledge of the subject but also in the speed of calculations due to the addition of electronic instrumentation and computer science [20].

In 1950, H. F. Blaney and W. D. Criddle developed a formula that allowed for the estimation of the amount of water needed for crop irrigation, a concept that the authors called consumptive use and that equated with the concept of potential evapotranspiration [25]. These researchers based their method on the grounds that the necessary water needed by a crop depends on the temperature; the hours of light and the vegetation cover [24]. In 1954, Turc proposed a method for calculating ET based on precipitation and temperature. The equation was empirically established by comparing rainfall and runoff from 254 watersheds. In that same year, Ivanov proposed an equation to estimate ET based on the mean temperature and relative humidity [24].

A few years later in the American Society of Civil Engineering's (ASCE) Ma- 
nual of Hydrology, ET was defined as “...the amount of water transpired by plants or retained in the leaves during their growth, plus the evaporated moisture from the soil surface and vegetation, expressed in inches" [12]. For his part Jensen presented in 1961 an equation that allowed the calculation of potential evapotranspiration in $\mathrm{mm}$ for each month as a function of temperature, solar radiation and relative humidity. The Jensen equation was developed for wetlands in Europe but was adjusted for cases where the relative humidity was less than $50 \%$ [26]. In 1962, Blaney presented an empirical formula based on experimental studies in the United States and several countries in Technical Bulletin No. 1275 of the United States Department of Agriculture. The Blaney equation estimates ET using air temperature, seasonal duration and the monthly percentage of daytime hours [21]. One year later in 1963, M. E. Jensen and H. R. Haise proposed an equation to estimate ET based on solar radiation and temperature [24].

Thus, almost 80 years elapsed since the first experimental stations were established in agricultural areas in the U.S. until the Penman-Monteith equation (1965) was published, to which a modification was made by J. L. Monteith to the formulation proposed by H. L. Penman in 1948 [27]. This method is one of the most widely used to estimate the evapotranspiration of reference crops in the world and is one of the most accurate.

Research on evapotranspiration and irrigation multiplied during the 60's, 70's and 80 's. Numerous publications in journals and books indicate that evapotranspiration was one of the most relevant topics in studies of hydrology and irrigation engineering [12]. These publications began to multiply in international congresses and meetings. In 1969, at the Seventh International Congress organized by the International Commission on Irrigation and Drainage (ICID), a specific topic entitled "Water Requirements for Crops" was discussed [28]. In 1977, the FAO published its bulletin number 24 that standardized concepts, approved criteria for the definition of and the most appropriate methods for estimating evapotranspiration.

Thus, for ET to be applied to any plant species, the term evapotranspiration of the reference crop (ETo) was introduced, with alfalfa being used by Jensen [29] and grasses by Doorenbos and Pruitt [30] who defined the evapotranspiration of the reference crop as the loss of water that would occur in a field that was totally covered with green vegetation of about 8 to $15 \mathrm{~cm}$ in height, and that in no time there was deficiency of water in the ground for the use by the vegetation. More recently, Smith [31] proposed a new definition based on the Penman-Monteith equation 1965, according to which the evapotranspiration of the reference crop is the evapotranspiration rate of a hypothetical crop of green grasses without consistent available water and with fixed values of height $(12 \mathrm{~cm})$, resistance of the vegetation cover $\left(69 \mathrm{~ms}^{-1}\right)$ and albedo (0.23). The consensus on the better definition of ETo is due to the efforts of many researchers and institutions that have been working on the subject, among the most prominent institutions being FAO and ASCE. Volume 24, "Water requirements for crops", edited by the FAO 
was a reference book in the study of the subject. It was not only the publications but also the congresses that approached the subject which began to take relevance. Thus, one of the first congresses on evapotranspiration was funded by the ICID and was carried out in Budapest, Hungary in May of 1977 [32]. In addition, one of the first monographic courses on the subject was organized in May 1982 in Bunbury, Western Australia [33]. In September of 1984, an international conference was held in Paris, France, specifically on crop water requirements where the subject was widely discussed. In December 1985, the American Society of Agricultural Engineers (ASAE) organized a symposium presenting the most important developments in evapotranspiration. The title of this event was "Advances in Evapotranspiration: theory, measurement and methods of application" [12]. In that same year, Hargreaves and Samani published their equation to estimate the potential evapotranspiration using only temperatures and solar radiation data, because many places of the world lack meteorological data as demanded by the Penman-Monteith equation [26].

Among the publications that compile conference lectures in Europe and America, the following stand out: 1) In Europe: that of the Netherlands Committee on Hydrology Research, which contains technical articles presented at Technical Meeting 44 at Ede (sic) in March 1985 in the Netherlands [34], 2) In America: the memoirs of the International Congress on "Evapotranspiration and Irrigation Scheduling" organized by the ASAE, held from the 3rd to 6th of November, 1996 in San Antonio, Texas.

Among the noteworthy books published on the subject are those edited by Jensen [12] called Evapotranspiration and irrigation water requirements, Manual Number 70 of the ASCE; the one published by Allen [35], in FAO Irrigation and Drainage paper No. 56 called Crop Evapotranspiration (Guidelines for computing crop water requirement), which describes the procedures for estimating evapotranspiration of the reference crop; and finally the attempt to standardize the estimate of the ETo by the Irrigation Association (IA), who asked the ASCE Committee on Evapotranspiration in Irrigation and Hydrology in May 1999 to define a standardized equation to estimate the evapotranspiration of the reference crop [36]. Currently, many books on hydrology, irrigation, climatology and especially the specialized literature on irrigation and drainage include evapotranspiration. Many case studies can be found on the subject.

Given the relevance of the subject, especially the Penman equation and within the context of the narrated historical context, this paper presents the theoretical foundations of Penman's equation of 1948 from the perspective of the first law of thermodynamics and the theory of energy balance, as a contribution for the students and engineers who use the Penman-Monteith equation in a utilitarian way, and to present the theoretical arguments that gave rise to it.

\section{Thermodynamics Foundations of the Penman Equation 1948}

The first law of thermodynamics is based on two basic concepts: work and heat. 
When an element performs work on a system, for example a saw that cuts a piece of wood, it heats up, so the heat produced is a result of the work done. These concepts can be applied to closed thermodynamic systems. A closed thermodynamic system is one that is limited by its boundaries, where the amount of contained matter does not change. It has been shown in the laboratory that in closed thermodynamic systems, changes in heat $(Q)$ are equal to changes in work $(W)$. According to Jones [37] this can be expressed as follows:

$$
\oint \delta Q_{c}=\oint \delta W
$$

In terms of energy $(E)$ the variations of $E$ in a system depend on the changes of the heat in the same system, minus the work done in that system, that is to say:

$$
\Delta E_{a}=Q_{c}-W
$$

Therefore, the energy stored in two instants of time in a different system:

$$
E_{a(t+\Delta t)}-E_{a(t)}=Q_{c}-W
$$

Furthermore, according to Figure $1, m_{s a, t}$ is defined as the mass of the open system at time $t, m_{s c, t}$ as the mass of the closed system at time $t, e$ as the input to the system, and $s$ as the system output, therefore you can write:

$$
m_{s c, t}=m_{e}+m_{s a, t}
$$

Thus, the energy at the instant of time, $t$, according to Equation (4), is equal to the energy of the open system at that instant, plus the energy in the form of flow velocity at the input of the system, therefore:

$$
E_{a(t)}=E_{a(s a, t)}+m_{e} e_{e}
$$

Then, the energy at the instant of time, $t+\Delta t$ is equal to the energy of the open system at that instant, plus the energy in the form of flow velocity at the output of the system, therefore:

$$
E_{a(t+\Delta t)}=E_{a(s a, t+\Delta t)}+m_{s} e_{s}
$$

Substituting Equations (5) and (6) into (3) we have:

$$
E_{a(s a, t+\Delta t)}+m_{s} e_{s}-\left(E_{a(s a, t)}+m_{e} e_{e}\right)=Q_{c}-W
$$

Accommodating terms and dividing the Equation (7) between $\Delta t$ you have the first law of thermodynamics applied to open systems which represents: the rate of change of the energy stored in the system with respect to time:

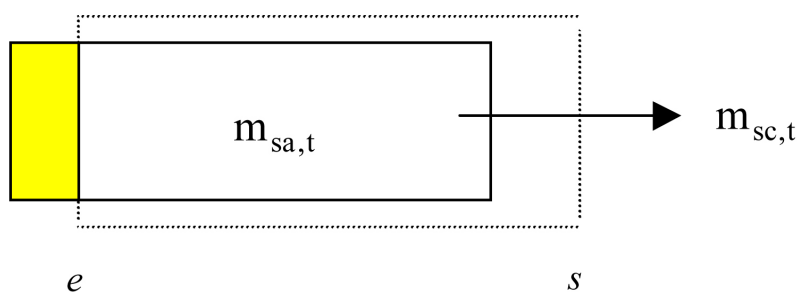

Figure 1. Open system in $t$ [37]. 


$$
\frac{\mathrm{d} E_{a(s a)}}{\mathrm{d} t}=\stackrel{\circ}{Q}-\stackrel{\circ}{W}_{\text {total }}+\stackrel{\circ}{m}_{e} e_{e}-\dot{\circ}_{s} e_{s}
$$

where:

$\stackrel{\circ}{Q}=$ Total heat transfer in one system per unit time

$\stackrel{\circ}{W}_{\text {total }}=$ Total work done by or on the system per unit time

$m_{e} e_{e}=$ Energy in the form of flow velocity at the system input

$m_{s} e_{s}=$ Energy in the form of flow velocity at the output of the system

$e=$ Energy per unit mass

On the other hand it is necessary to consider that if a quantity of matter crosses the limit of a system, work is done by or on the system. Such work (Wtotal) per unit of time is composed of two parts [37]: 1) External work and 2) Work Flow:

$$
W_{\text {total }}=\stackrel{\circ}{W}+\stackrel{\circ}{m_{s}} P_{s} V_{s}-\stackrel{\circ}{m}_{e} P_{e} V_{e}
$$

where:

$\stackrel{\circ}{W}=$ External work per unit of time

$m_{s} P_{s} V_{s}=$ Flow work per unit mass and time (work performed by the system, hence its positive sign).

$m_{e} P_{e} V_{e}=$ Work flow per unit mass and time (work done on the system, hence its negative sign).

Substituting (9) into (8) and factoring if the equation that represents the rate of change of energy in time in an open system, with one-dimensional flow in the its boundaries:

$$
\frac{\mathrm{d} E_{a}}{\mathrm{~d} t}=\stackrel{\circ}{\mathrm{Q}}-\stackrel{\circ}{\mathrm{W}}+\dot{\circ}_{e}\left(e_{e}+P_{e} V_{e}\right)-\dot{m}_{s}\left(e_{s}+P_{s} V_{s}\right)
$$

Thus, in a differential piece of soil subject to the action of net solar radiation $(\mathrm{Rn})$ its rate of energy variation in said system (not subject to any external work) will depend on the heat transfer received by said radiation, as well as the work of flow and the energy entering and leaving the system. Therefore, the equation representing the rate of change of energy versus time in said soil differential as:

$$
\frac{\mathrm{d} E_{a}}{\mathrm{~d} t}=\stackrel{\circ}{Q}+\dot{\circ}_{e}\left(e_{e}+P_{e} V_{e}\right)-\dot{m}_{s}\left(e_{s}+P_{s} V_{s}\right)
$$

where:

$\stackrel{\circ}{Q}=$ Is the energy transfer due to net radiation.

$m_{e}\left(e_{e}+P_{e} V_{e}\right)=$ Is the energy that enters the system.

$m_{s}\left(e_{s}+P_{s} V_{s}\right)=$ Is the energy that comes out of it.

If also: $\stackrel{\circ}{Q}=R n ; \quad \dot{m}_{e}\left(e_{e}+P_{e} V_{e}\right)=L_{p} F_{p}+\Delta_{h} ; \quad \dot{m}_{s}\left(e_{s}+P_{s} V_{s}\right)=\lambda E+H+G$, then the equation that represents the energy balance in a differential piece of the earth's surface is:

$$
\frac{\mathrm{d} E_{a}}{\mathrm{~d} t}=R n+\left(L_{p} F_{p}+\Delta_{h}\right)-(\lambda E+H+G)
$$


Thus, according to Brutsaert [38], the energy balance equation for a soil surface exposed to the action of solar energy is:

$$
\frac{\mathrm{d} E_{a}}{\mathrm{~d} t}=R n \downarrow+L_{p} F_{p} \downarrow+\Delta h \downarrow-\lambda E \uparrow-H \uparrow-G \uparrow
$$

The terms of a positive sign $(\downarrow)$ are flows that enter the soil differential layer and the negative sign $(\uparrow)$ are flows that leave the same layer.

where:

$\lambda E=$ Latent heat of vaporization

$H=$ Heat sensitive to air

$L_{p} F_{p}=$ Product of the thermal conversion factor for $\mathrm{CO}_{2}$ fixation $\left(L_{p}\right)$ by the specific $\mathrm{CO}_{2}$ flow $\left(F_{p}\right)$

$G=$ Heat sensitive to soil

$\Delta h=$ Advection energy within the specific layer or flow (evaporation)

$\frac{\partial E_{a}}{\partial t}=$ Energy rate versus time in the soil differential layer

For practical purposes, the term $\Delta h$ in the evaporation phenomenon is negligible, since in calculating it, its magnitude is very small compared to the rest of the terms [38]. The $F_{p} L_{p}$ product does not affect the evaporation phenomenon alone and is usually important at two moments, after sunrise and near sunset, since it can reach values of net radiation [39]. However, in calculations for daily periods this term is negligible [38]. On the other hand, the stored energy rate per unit area is negligible in a soil differential layer. Under these considerations the rate of energy stored per unit area in a piece of differential soil is:

$$
\frac{\mathrm{d} E_{a}}{\mathrm{~d} t}=R n \downarrow-\lambda E \downarrow-H \downarrow-G \downarrow
$$

Thus the total accumulated energy can be written as:

$$
E_{a}=\int_{t_{1}}^{t_{2}}(R n-\lambda E-H-G) \mathrm{d} t
$$

In a daily balance the rate of energy per unit of time stored in a differential soil surface is negligible, therefore:

$$
\frac{\mathrm{d} E_{a}}{\mathrm{~d} t}=0
$$

Thus:

$$
R n=\lambda E+H+G
$$

where:

$E=$ Evaporation rate

Thus the simplest equation for estimating evaporation, which comes from the energy balance equation, depends on the incident of net radiation minus the sensible heat of the air and the soil, divided by the latent heat:

$$
E=\frac{R n-H-G}{\lambda}
$$




\section{Physical Foundations of Penman's Equation of 1948 Based on Energy Balance Theory}

The rate of change over time of energy manifested as sensible heat $(H)$ in air is proportional to the rate of change of energy of a mass of water vapor [12]:

$$
\frac{\mathrm{d}}{\mathrm{d} t} \lambda E \approx \frac{\mathrm{d}}{\mathrm{d} t} H
$$

The equality of the above equation is achieved with the B constant of Bowen:

$$
B=\frac{H}{\lambda E}
$$

Bowen expressed the above relationship showing the impossibility of dealing with evaporation $(E)$ without considering sensible heat $(H)$ in the analysis of the energy balance equation [38]. Thus, Substituting (20) into (17) has:

$$
\lambda E=R n-B \lambda E-G
$$

Thus:

$$
\lambda E=\frac{R n-G}{1+B}
$$

According to [12] the Equation (23) comes from the next knowledge: for an ideal gas the rate of change of the enthalpy $H$ (also called sensible heat) is proportional to the temperature changes, that is to say $\mathrm{d} h \sim \mathrm{d} t$. In order to equalize the equation, a constant $\gamma$ is introduced which is the specific weight of the air, thus the differential changes of sensible heat can be re-written as:

$$
\mathrm{d} H=\gamma \mathrm{d} T
$$

If the mechanism of atmospheric transport of sensible heat is very similar to that of water vapor in a differential air mass [12], [38], then we can write:

$$
\mathrm{d} \lambda E \cong \mathrm{d} e_{v}
$$

where $\mathrm{d} e_{v}=\Delta e_{v}$ is the vapor pressure deficit at saturation in $\mathrm{kPa}$. Thus, from Equations (23) and (24) we have:

$$
\gamma \mathrm{d} T \approx \mathrm{de} e_{v}
$$

Introducing the proportionality constant $B$, we have the following expression:

$$
\begin{gathered}
\gamma \mathrm{d} T=B\left(\mathrm{~d} e_{v}\right) \\
B=\frac{\gamma \mathrm{d} T}{\mathrm{~d} e_{v}}
\end{gathered}
$$

Thus:

$$
B=\gamma \frac{\left(T_{o}-T_{z}\right)}{e_{o}^{o}-e_{z}}
$$

where:

$$
\begin{aligned}
& e_{o}^{o}=\text { Steam pressure at saturation of water surface }(\mathrm{kPa}) \\
& e_{z}=\text { Air vapor pressure at height } z(\mathrm{kPa}) \\
& T_{z}=\text { Temperature at height } z\left({ }^{\circ} \mathrm{C}\right)
\end{aligned}
$$


$T_{o}=$ Wet bulb temperature $\left({ }^{\circ} \mathrm{C}\right)$

Substituting (28) into (22) results in:

$$
\lambda E=\frac{R n-G}{1+\gamma\left(\frac{T_{o}-T_{z}}{e_{o}^{o}-e_{z}}\right)}
$$

On the other hand, in 1802 Dalton published an equation to estimate evaporation as [38]:

$$
E=f_{D}(\hat{u})\left(e_{o}^{o}-e_{z}\right)
$$

where $f_{D}(\hat{u})$ is a function of wind speed. For his part, Penman defined $E_{V}$ as the value of evaporation $(E)$, if $e_{o}^{o}$ was replaced by $e_{z}^{o}$, that is, at this key point in the deduction of his equation, Penman 1948 replaced the value of the saturation vapor pressure at the water surface temperature $\left(e_{o}^{o}\right)$, by the vapor pressure at saturation of the air at height $z\left(e_{z}^{o}\right)$, so Equation (30) can be rewritten as:

$$
E v=f_{D}(\hat{u})\left(e_{z}^{o}-e_{z}\right)
$$

Thus, Penman established the following relation:

$$
\frac{E v}{E o}=\frac{f_{D}(\hat{u})\left(e_{z}^{o}-e_{z}\right)}{f_{D}(\hat{u})\left(e_{o}^{o}-e_{z}\right)}
$$

where $E o$ is the evaporation rate depending on the density of latent heat flux $\left(\mathrm{mmd}^{-1}\right)$. Equation (32) can be rewritten as follows:

$$
\frac{E v}{E o}=\frac{\left(e_{o}^{o}-e_{z}\right)-\left(e_{o}^{o}-e_{z}^{o}\right)}{\left(e_{o}^{o}-e_{z}\right)}
$$

It is simplified as follows:

$$
\frac{E v}{E o}=1-\frac{e_{o}^{o}-e_{z}^{o}}{e_{o}^{o}-e_{z}}
$$

In Equation (34) the vapor pressure term appears, which is a measure of the tendency of the liquid to be vaporized. Its value increases with temperature, coinciding in the case of the liquids with atmospheric pressure when the boiling temperature is reached. A fundamental step by Penman 1948 to deduce his equation was to assume that the slope of the vapor pressure curve was directly proportional to the vapor pressure difference at saturation of water and air, and inversely proportional to the temperature difference to air vapor pressure at $Z$ height and wet bulb temperature [12]. The above can be formally expressed through the concept of the first derivative of a function by the method of the incremental quotient; so, allowing $f(x)$ be a function the slope $f^{\prime}(x)$ is given by:

$$
f^{\prime}(x)=\lim _{\Delta T \rightarrow 0} \frac{f(T+\Delta T)-f(T)}{\Delta T}
$$

Assuming that: 


$$
\begin{gathered}
f(T+\Delta T)=e_{o}^{o} \\
f(T)=e_{z}^{o} \\
\Delta T=(T+\Delta T)-T=T_{o}-T_{z} \\
f^{\prime}(x)=\Delta
\end{gathered}
$$

Then, by replacing (36) to (39) in (35), we have the slope of the Penman vapor pressure curve:

$$
\Delta=\frac{e_{o}^{o}-e_{z}^{o}}{T_{o}-T_{z}}
$$

Clearing $\left(T_{o}-T_{z}\right)$ of $(40)$ :

$$
T_{o}-T_{z}=\frac{e_{o}^{o}-e_{z}^{o}}{\Delta}
$$

Substituting (41) into (29) and operating algebraically results in the following equation:

$$
\lambda E o=\frac{R n-G}{1+\gamma\left(\frac{\frac{e_{o}^{o}-e_{z}^{o}}{\Delta}}{\frac{e_{o}^{o}-e_{z}}{1}}\right)}=\frac{R n-G}{1+\gamma\left(\frac{e_{o}^{o}-e_{z}^{o}}{\Delta\left(e_{o}^{o}-e_{z}\right)}\right)}=\frac{R n-G}{1+\frac{\gamma}{\Delta}\left(\frac{e_{o}^{o}-e_{z}^{o}}{e_{o}^{o}-e_{z}}\right)}
$$

Substituting (34) into (42) results in:

$$
\lambda E O=\frac{R n-G}{1+\frac{\gamma}{\Delta}\left(1-\frac{E v}{E o}\right)}
$$

Algebraically operating (43) has:

$$
\begin{gathered}
\lambda E o=\frac{R n-G}{1+\frac{\gamma}{\Delta}-\frac{\gamma}{\Delta} \frac{E v}{E o}}=\frac{R n-G}{1+\frac{\gamma \Delta E o-\Delta \gamma E v}{\Delta^{2} E o}=\frac{R n-G}{\frac{\Delta^{2} E o+\gamma \Delta E o-\Delta \gamma E v}{\Delta^{2} E o}}} \\
\lambda E O=\frac{R n-G}{\frac{\Delta^{2} E o+\gamma \Delta E o-\Delta \gamma E v}{\Delta^{2} E o}}=\frac{\Delta^{2} E o(R n-G)}{\Delta^{2} E o+\gamma \Delta E o-\Delta \gamma E v}=\frac{\Delta^{2} E o(R n-G)}{\Delta E o\left(\Delta+\gamma-\frac{\gamma E v}{E o}\right)}
\end{gathered}
$$

Simplifying (45):

$$
\lambda E o=\frac{\Delta(R n-G)}{\Delta+\gamma-\gamma \frac{E v}{E o}}
$$

Accommodating terms:

$$
\begin{gathered}
\lambda E o \Delta+\lambda E o \gamma-\lambda E o \gamma \frac{E v}{E o}=\Delta(R n-G) \\
\lambda E o \Delta+\lambda E o \gamma=\Delta(R n-G)+\lambda \gamma E v \\
\lambda E o(\Delta+\gamma)=\Delta(R n-G)+\lambda \gamma E v
\end{gathered}
$$

Clearing $\lambda E o$ : 


$$
\lambda E o=\frac{\Delta(R n-G)+\lambda \gamma E v}{(\Delta+\gamma)}
$$

Finally, Penman's equation 1948 for estimating evaporation is:

$$
\lambda E o=\left(\frac{\Delta}{\Delta+\gamma}\right)(R n-G)+\left(\frac{\gamma}{\Delta+\gamma}\right) \lambda E v
$$

With Equation (51), the evaporation of a free water surface can be estimated, considering an albedo of 0.05 [12]. The first member of the Equation (51) considers the energy required to cause evaporation and the second member the energy required to remove water vapor; therefore Equation (51) was the first combined method deduced by Penman, where the variable $E_{V}$ can be estimated with Equation (31).

\section{Conclusion}

In the last 130 years numerous researchers from a number of countries have developed a large number of methods for estimating ETo, among them the Penman equation of 1948 and Penman-Monteith equation of 1965. There are numerous computer programs developed by research centers and universities using these methods for research or utility purposes. Many of these programs are used by field engineers who do not know the origin and the physical foundations of these equations. In this paper we presented the detailed theoretical development and physical foundations of Penman's equation of 1948 from the perspective of the first law of thermodynamics and the theory of energy balance, as a contribution for the students and engineers who use these equations to have its rich historical and theoretical framework.

\section{Acknowledgements}

Special thanks to Michael J. Greces for translating this paper.

\section{References}

[1] Parmele, L.H. (1972) Errors in Output of Hydrologic Model Due to Errors in Input of Potential Evaporanspiration. Water Resources Research, 8, 348-359. https://doi.org/10.1029/WR008i002p00348

[2] Skaggs, R.W. (1980) Method for Design and Evaluation of Drainage Water Management System for Soil with Hight Water Table Soils. DRAINMOD Reference Rep., USDA Soil Conservation Service, Whashington, DC.

[3] Purisinsit, P. (1982) Evaluation of Two Hydrologic Models for the North Carolina Blacklands. PhD Thesis, North Carolina State University, Raleigh.

[4] McCarthy, E.J. (1990) Modification, Testing and Application of a Hydrologic Model for a Drained Forest Watershed. PhD Thesis, North Carolina State University, Raleigh.

[5] Choisnel, E., de Villete. and Lacroze, F. (1992) Une approche iniformisse du calcul de L'vapotranspiration potentielle pour Lénsemble des PAYS de la communaute europeene. Un système D'Information agronomique pour La Communaute Europeene, Centre Commun de Recherche, Commission des Communaute 
Europeennes.

[6] Omary, M. and Izuno, F.T. (1995) Evaluation of Sugarcane Evapotranspiration from Water Table Data in Everglades Agricultural Area. Journal of Agricultural Water Management, 27, 309-319. https://doi.org/10.1016/0378-3774(95)01149-D

[7] Hammed, T., Mariño, M.A. and Shumway, R.H. (1995) Evapotranspiration Transfer-Function-Noise Modeling. Journal of Irrigation and Drainage Engineering-Asce, 12, 159-159. https://doi.org/10.1061/(ASCE)0733-9437(1995)121:2(159)

[8] Michalopoulo, H. and Papaioannou, G. (1991) Reference Crop Evapotranspiration over Greece. Journal of Agricultural Water Management, 20, 209-221. https://doi.org/10.1016/0378-3774(91)90018-E

[9] Hashmi, M.A. and García, L.A. (1998) Spatial and Temporal Errors in Estimating Regional Evapotranspiration. Journal of Irrigation and Drainage Engineering-Asce, 124, 108-114. https://doi.org/10.1061/(ASCE)0733-9437(1998)124:2(108)

[10] Al-Ghobari, H.M. (2000 b) Estimation of Reference Evapotranspiration for Southern Region of Saudi Arabia. Irrigation Science, 19, 81-86.

https://doi.org/10.1007/s002710050004

[11] Hargreaves, H.G. (1994) Defining and Using Reference Evapotranspiration. Journal of Irrigation and Drainage Engineering, 120, 1132-1139. https://doi.org/10.1061/(ASCE)0733-9437(1994)120:6(1132)

[12] Jensen, M.E., Burman, R.D. and Allen, R.G. (1990) Evapotranspiration and Irrigation Water Requirement. ASCE Manuals and Report on Engineering Practices No. 70, New York, 332 p.

[13] Brutsaert, W. (1982) Evaporation into the Atmosphere. D. Reidel Publishing Co., Dordrecht, Boston, London, 299 p. https://doi.org/10.1007/978-94-017-1497-6

[14] Harris, F.S. (1920) The Duty of Water in the Cache Valley, Utah. Utah Agr., Exp., Bull. 173, 16 p.

[15] Hemphill, R.G. (1992) Irrigation in Northern Colorado. USDA Agri. Bull. 1026, 85 p.

[16] Israelsen, O.W. and Winsor, L.M. (1922) The Net Duty of Water in the Sevier Valley, Utah. Utah Agr. Exp. Stn. Bull. 182, 36 p.

[17] Lewis, M.R. (1919) Experiment on the Proper Time and Amount of Irrigation. Twin Falls Exp. Stn 1914 and 1916. USDA, with Twin Falls Country Comm. Twin Falls Canal Co., and Twin Falls Comm. Club.

[18] Widstoe, J.A. (1912) The Production of Dry Matter with Different Quantities of Water. Utah Agr. Exp., Bull. 16. 64 p.

[19] Briggs, L.J. and Shantz, H.L. (1913) The Water Requirements of Plants. I. Investigation in the Great Plains in 1910 and 1911. US. Dep., Agr. Bur. Plant Indr. Bull. 284. $49 \mathrm{p}$.

[20] Penman, H.L. (1948) Natural Evapotranspiration from Open Water, Bare Soil and Grass. Proceedings of the Royal Society of London, Series A, 193, 120-146.

https://doi.org/10.1098/rspa.1948.0037

[21] Blaney, H.F. (1962) Determining Consumptive Use and Irrigation Water Requirement. US. Dep Agr. Bull. 1275. 59 p.

[22] Blaney, H.F., Taylor, C.A. and Young, A.A. (1930) Rainfall Penetration and Consumptive Use of Water in Santa Ana Valley and Coastal Plain. Calif. Dep. of Public Works, Div. of Water Resour. Bull. 33. 158 p.

[23] Thornthwaite, C.W. (1948) An Approach toward a Rational Classification of Cli- 
mate. Geographical Review, 38, 5-94. https://doi.org/10.2307/210739

[24] Sánchez, M.M. (2001) Métodos de evapotraspiración utilizados en Chile. Revista de Geografía Norte Grande, 28, 3-10.

[25] Blaney, H.F. and Criddle, W.D. (1950) Determining Water Requirements in Irrigated Area from Climatological Irrigation Data. US Dep. of Agr. Tech. Pap. No. 96. $48 \mathrm{p}$.

[26] Mundo-Molina, M. (2002) Physical-Mathematical Fundamentals and Methods for Estimating and Forecasting ETo for Irrigation Purposes in the Yaqui Valley, Sonora, Mexico. Doctoral Thesis, Polytechnic University of Madrid.

[27] Monteith, J.L. (1965) Evaporation and Environment. Symposia of the Society for Experimental Biology, 19, 205-234.

[28] ICID (1969) Memoria técnica. 7o Congreso Internacional de Riego y Drenaje. México, D.F.

[29] Jensen, M.F. and Erie, I. (1971) Sugarbeet Production: Principles and Practices. J. Irrigation and Water Management, Chapter 8, The Iowa State University Press, Ames.

[30] Doorenbos, J. and Pruitt, W.O. (1977) Crop Water Requirements. Irrigation and Drainage Paper 24. FAO, Roma, 144 p.

[31] Smith, M., Allen, R.G., Monteith, J.L., Perrier, A., Pereira, L.S. and Segeren, A. (1991) Report of the Expert Consultation on Procedures for Revision of FAO Guidelines for Prediction of Crop Water Evapotranspiration. Report of the Expert Consultation on Procedures for Revision of FAO Guidelines for Prediction of Crop Water Requirements. FAO, Food and Agricultural Organization of the United Nations, Rome.

[32] Perrier, A. and Jensen, M.E. (1979) Question 1 Terminology, and Question 2 Measurement Methods. Ann. Rpt. ICID Internl. round Table Conf. on Evapotranspiration, Budapest, A-120-A-145.

[33] Sharma, M.E. (1984) Evapotranspiration from Plan Communities. Elsevier Science Publishers. B.V., New York.

[34] Hooghart, J.C. (1987) Evaporation and Wheather. TNO Comm. on Hydrol. Res., Proc., and Info. No. 39, 111 p.

[35] Allen, R.G., Pereira, L.S., Raes, D. and Smith, M. (1998) Crop Evapotranspiration-Guidelines for Computing Crop Water Requirements. FAO Irrigation and Drainage Paper 56. Food and Agriculture Organization, Rome.

[36] Walter, I.A., Allen, R.G., Elliot, R., Jensen, M.E., Itenfisu, D., Mecham, B., Howel, T.A., Snyder, R., Brown, P., Echings, S., Spofford, T., Hattendorf, M., Cuenca, R.H. and Wright, J.L. (2000) ASCE's Standarized Reference Evapotranspiration Equation. Watershed Management and Operation Management 2000. Science and Engineering Technology for the Millenium.

[37] Jones, J.B. and Dugan, R.E. (2007) Ingeniería termodinámica. Prentice-Hall Hispanoamérica, México.

[38] Brutsaert, W. (1984) Evaporation into the Atmosphere. Theory, History and Application. D. Reidel Publishing Co., Dordrecht, Boston, London.

[39] Steward, J.B. and Thom, A.S. (1973) Energy Budget in Pine Forest. Quarterly Journal of the Royal Meteorological Society, 99, 154-170.

https://doi.org/10.1002/qj.49709941913 